\title{
Research on Stereotypes on Only Child for College Students
}

\author{
Wu Zhen ${ }^{1}$, Liang Jieshuang ${ }^{1 *}$, Wang Jing ${ }^{2}$ \\ ${ }^{1}$ Department of Psychology, Tianjin University of Technology and Education \\ Tianjin 300222, China \\ ${ }^{2}$ Department of Education, Hebei Normal University of Science and Technology \\ Hebei 0666004, China
}

\begin{abstract}
Since the implementation of family planning in China in 1979, the only-child group has become increasingly large and has gradually attracted public attention. This study explores whether college students have a stereotyped impression of the only child. If so, what are the specific contents and characteristics. Using the only-child stereotype questionnaire, 320 college students were randomly selected to fill in the questionnaire. The following conclusions show: (1) The stereotypes of college students on the only child are "wasteful, confident, short-tempered, lonely, haughty, and strong dependent"; (2) College students from rural areas have deeper stereotypes on only child than urban college students; (3) The only-child college students and non-only-child students show a clear "outside group derogatory effect" in only-child stereotype; (4) There is no gender difference in college students' stereotypes on only child.
\end{abstract}

Keywords-Only child; Stereotypes; Negative Stereotypes; Positive Stereotypes; College Students

\section{INTRODUCTION}

China began implementing the only-child policy in 1979, and since then, the number of only-children has increased. The public's attention to this group has increased dramatically and related research has become more abundant. As the society is frequently exposed to negative news about them, the group often shows people in a negative image, so people gradually have inherently bad impressions on only child. Stereotype is a set of concepts about the characteristics, attributes and behaviors of specific groups, or the cognitive representations of the features or attributes associated with social groups and their members [1]. Previous studies on stereotype focused on the gender, age, race and occupation, etc [2-5]. However, the study of stereotypes on only child is relatively inadequate. This present study defines the stereotypes on only child as relatively widespread and fixed views and concepts of the public about the only child's property in social life. The research of the stereotype on only child in foreign countries is more about the difference in personality between the only child and the nononly child. For example, Nyman (1995) asked college students to describe the only child with personality adjectives. The only child was considered to be the most unpopular [6]. Herrera, Zajonc, Wieczorkowska and Cichomski's (2003) findings on the birth sequence showed that people believed that the only child was the most unreasonable in all birth sequences [7]. Research on the only child in China focuses on the personality and interpersonal relationship. Studies showed that college students had a clear stereotype on only child and believed that oneness and enthusiasm (interpersonal relationships are good or bad) were related to each other, and that non-only child were more highly evaluated [8]. On the whole, the research on the stereotype of the only-children is still insufficient and it is necessary to further explore it.

\section{METHODS}

\section{A. Participants}

In Hebei Province in China, a number of colleges and were selected. 320 questionnaires were distributed and 305 were collected with an effective rate of $95.31 \%$

\section{B. Measures}

In this study, the Only-child Stereotype Adjective Questionnaire compiled by Bao Leiping (2010) was used [9]. A total of 15 items were scored from 1 (completely disagree) to 5 (completely agree). The higher the scores, the more stereotyped on the only child. The questionnaire contains two dimensions: positive and negative dimensions in which questions $2,4,6,8$, and 11 belong to positive dimension and others belong to negative dimension.

\section{Statistical Methods}

SPSS19.0 statistical software was used to process the data. The questionnaire scores were normally distributed and were described by means of (mean \pm standard deviation). A singlesample t-tests was used to compare whether college students had stereotypes and stereotyped contents on only child. An independent sample t-test was used to compare the difference in stereotypes among college students in urban and rural areas, in only-child students and non-only students and in different genders. 


\section{RESULTS}

Participants' demographics is shown in Table I

TABle I Demographics $(N=305)$

\begin{tabular}{cccc}
\hline Contents & & Numbers & Percentages \\
\hline \multirow{2}{*}{ Gender } & Male & 100 & $42.62 \%$ \\
& Female & 175 & $57.38 \%$ \\
Whether or not the only cchi & Yes & 99 & $32.46 \%$ \\
From urban or rural area & No & 206 & $67.54 \%$ \\
& Urban & 90 & $29.51 \%$ \\
Grades & Rural & 215 & $70.49 \%$ \\
& Freshman & 20 & $6.56 \%$ \\
& Sophomore & 61 & $20.00 \%$ \\
& Junior & 74 & $24.26 \%$ \\
\hline
\end{tabular}

\section{A. Stereotypes of only child in college students}

The results showed that there were scores of 6 entries significantly higher than the median value of 3 , that was, the adjectives that college students considered to describe only child were "wasteful", "confident", "short-tempered", "lonely", "haughty" and "dependent heavily". The average score was not lower than 3.15. Except "confident", the other five words related to personality were negative. While scores of 3 entries were significantly lower than the median value of 3 , that was, college students believed that these adjectives which did not meet the only child were "with personality", "willful", "fashionable". The average score was not higher than 2.70 (Table II).

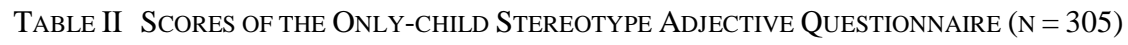

\begin{tabular}{lcc}
\hline Adjectives & $\mathrm{M} \pm \mathrm{SD}$ & $t$ scores \\
\hline Wasteful & $3.30 \pm 1.032$ & $5.048^{* * *}$ \\
Confident & $3.29 \pm 1.001$ & $5.034 * * *$ \\
Short-tempered & $3.29 \pm 1.055$ & $4.732 * * *$ \\
Lonely & $3.24 \pm 1.108$ & $3.771 * * *$ \\
Haughty & $3.17 \pm 1.031$ & $2.888 * *$ \\
Dependent heavily & $3.15 \pm 1.119$ & $2.304 *$ \\
Rich (Have good material conditions) & $3.04 \pm 1.055$ & 0.597 \\
Clever & $3.03 \pm 1.110$ & 0.464 \\
Spoiled & $3.00 \pm 0.909$ & 0.063 \\
Selfish & $2.94 \pm 1.124$ & -0.866 \\
Unsociable & $2.92 \pm 1.041$ & -1.265 \\
Self-centered & $2.91 \pm 0.991$ & -1.560 \\
With personality & $2.70 \pm 1.077$ & $-4,944 * * *$ \\
Willful & $2.68 \pm 0.904$ & $-6.206 * * *$ \\
Fashionable & $2.51 \pm 1.010$ & $-8.502 * * *$ \\
\hline
\end{tabular}

Note: $* p<0.05, * * p<0.01, * * * p<0.001$. 
B. The stereotypes on the only child among college students from different urban and rural areas

In the overall stereotype and negative stereotype dimension, the scores of college students from rural areas were significantly higher than those of college students from urban areas. However, there was no significant difference between the two in positive stereotype dimension (Table III).

TABLE III THE STEREOTYPES SCORES OF COLLEGE STUDENTS FROM URBAN AND RURAL AREAS ( $\mathrm{N}=305)$

\begin{tabular}{lccc}
\hline \multicolumn{2}{c}{ From urban or rural areas } & $\mathrm{M} \pm \mathrm{SD}$ & $t$ scores \\
\hline \multirow{2}{*}{ Overall stereotype } & Urban & $2.89 \pm 0.622$ & $2.220 *$ \\
& Rural & $3.06 \pm 0.614$ & \\
\multirow{2}{*}{ Positive stereotype } & Urban & $3.05 \pm 0.747$ & 0.289 \\
& Rural & $3.03 \pm 0.667$ & $2.910 * *$ \\
\multirow{2}{*}{ Negative stereotype } & Urban & $1.87 \pm 0.478$ & \\
& Rural & $2.05 \pm 0.499$ & \\
\hline
\end{tabular}

Note: $* p<0.05, * * p<0.01$.

C. The stereotypes on the only child among only-child college students and non-only-child students

In the overall stereotype and negative stereotype dimension, the scores of only-child college students were significantly higher than those of non-only-child college students. However, there was no significant difference between the two in positive stereotype dimension (Table IV).

TABLE IV THE STEREOTYPES SCORES OF ONLY-CHILD-STUDENTS AND NON-ONLY-CHILD STUDENTS ( $\mathrm{N}=305)$

\begin{tabular}{lccc}
\hline & Only-child students or non-only-child students & $\mathrm{M} \pm \mathrm{SD}$ & $t$ scores \\
\hline \multirow{2}{*}{ Overall stereotype } & Only-child students & $2.80 \pm 0.617$ & $4.224 * * *$ \\
& Non-only-child students & $3.11 \pm 0.598$ & \\
Positive stereotype & Only-child students & $3.07 \pm 0.693$ & 0.724 \\
& Non-only-child students & $3.01 \pm 0.690$ & \\
Negative stereotype & Only-child students & $1.78 \pm 0.537$ & $5.348 * * *$ \\
& Non-only-child students & $2.11 \pm 0.442$ & \\
\hline
\end{tabular}

Note: $* * * p<0.001$.

D. The stereotypes on the only-child among college students in different genders

There was no significant difference of scores in the overall stereotype scores and 2 dimensions between male college students and female students (Table V).

TABLE $\mathrm{V}$ THE STEREOTYPES SCORES OF MALE STUDENTS AND FEMALE STUDENTS ( $\mathrm{N}=305$ )

\begin{tabular}{llll}
\hline & Gender & $\mathrm{M} \pm \mathrm{SD}$ & $t$ scores \\
\hline Overall stereotype & Male & $2.93 \pm 0.706$ & -1.900 \\
& Female & $3.07 \pm 0.543$ & \\
Positive stereotype & Male & $2.96 \pm 0.710$ & -1.605 \\
& Female & $3.09 \pm 0.672$ & \\
Negative stereotype & Male & $1.94 \pm 0.546$ & -1.666 \\
& Female & $2.04 \pm 0.458$ & \\
\hline
\end{tabular}




\section{DISCUSSION}

\section{A. College students have stereotypes on only child.}

The results of this study showed that college students did have a stereotypical impression of only child. Among the 15 adjectives in the Only-children Stereotype Adjective Questionnaire, 6 adjectives were considered by college students as an impression of the only child. They were "wasteful", "confident", "short-tempered", "lonely", "haughty" and "dependent heavily". Only one of these words, "confident", is a positive word, and the rest contains negative emotions. It shows that college students generally believe that the group of only child is more confident than non-only child and that they can deal with the situation with confidence. This may be related to the absolute attention from the family since they are young, which needs to be further studied.

Secondly, the negative stereotypes of college students on only child were "wasteful", "short-tempered", "lonely", "haughty" and "dependent heavily". These adjectives are closely related to personality, and the reasons need to be analyzed. This study considers the following two points: First, surveyed college students made the above evaluation based on the only child they knew about and formed a negative impression. It may be that some only children they know do have similar behavioral actions. According to the theory of social cognition, since the formation and memory of other people's impressions are affected by the "primacy effect" and schema, they will have a negative impression on the only-child group. Second, the mass media plays a very important role in impression formation. The reports on the only child in China has a negative influence on the majority, and the number of these reports related to the personality and characteristics of the only child is great. Therefore, it inevitably has an impact on the cognition of college students, which leads to the negative impression on the only child. For example, in the news, it is often reported that because the pressure to support the elder is so great that the only child refuses to look after his or her parents or send parents to sanatorium for care. Such cases are not uncommon, and indeed cause deep thoughts and worries. News like these makes the public form a bad impression on the one-child group. Therefore, the news media has an inescapable responsibility for the formation of a negative stereotype of the only child. This is consistent with the research of Xiao Fuqun and Feng Xiaotian (2010) [10].

Additionally, the adjectives that college students believed to be inconsistent with only child were "with personality", "willful", "fashionable". It shows that in the eyes of college students, the one-child group is not labeled with personality or willfulness, and the understanding of the only child is not only negative, but also have some objective components, which makes the present study more convincing.

\section{B. Urban-rural differences of the only-child stereotype}

In the overall stereotype and negative dimension, college students from townships had deeper stereotypes on the only child. Xiao Fuqun (2010) once said: "There are differences in the production mechanism of the only child in urban and rural areas" [10].

Since the implementation of family planning in China in the 1970s, due to the higher level of urban economic development and industrialization, the government has stricter supervision of urban areas, and coupled with the relatively high awareness of the people in the city, family planning has been universally implemented in cities. People in towns are relatively conservative in thinking, and generally prefer sons to daughters. Therefore, family planning policy has been implemented slowly in towns. Although the current situation has improved, the number of only child in towns is still relatively small compared to that in urban areas. So college students from cities can often come into contact with only child. The understanding of the group is more objective and real, and stereotypes are not deep. However, college students from towns are more exposed to non-only-child group and have fewer opportunities to contact with only child. They can only form an impression on the only child through other information from the outside world. Therefore, they are easily affected by external factors such as the media, which is not so objective sometimes. In addition, most urban students are only child, and the stereotype of the only-child group is not naturally deep. In contrast, there are too many non-only-child in rural areas, and the only-child group is an out-group for them, so it shows a deeper stereotype.

\section{Differences of stereotypes on the only-child of only-child college students and non-only-child students}

In the overall stereotype and negative dimension, the non-only-child college students' stereotype was stronger than the only-child students, which showed that the non-only-child students have more negative stereotypes on the only child. This phenomenon shows the effect of "out-group derogatory". This is in part consistent with the study of Cui Yan's (2013) [11]. The inner-outer group preference effect of stereotypes tells us that people tend to have a positive evaluation of the group to which they belong while give a negative evaluation of the external groups. The results of this present study exactly coincided with the latter part of the theory, that is, it only reflected the "derogatory effects of the external groups". Nononly-child college students were more likely to produce negative stereotypes on the only-child group. This present study did not reflect the "interior group preference" effect. The reasons for the analysis may be that Chinese people are more introverted and modest, and the only-child students are more likely to evaluate themselves higher than the results presented by the questionnaire. If the implicit attitude is measured, this may be pronounced. 


\section{Gender differences in college students' stereotype on only child}

The results of this study showed that there was no significant difference in the stereotype on only child between male college students and female college students. The possible reason is that current male and female college students are relatively ideologically liberated, and they have many opportunities to communicate with each other. Therefore, the views on things have a certain degree of similarity. However, from the data in Table $\mathrm{V}$, it can be seen that female college students' scores in the overall stereotype and two dimensions are still slightly higher than the male students. To a certain extent, female college students are relatively sensitive and conservative. They are more stubborn in their impression of the only child while male college students are more free-minded and do not rigidly adhere to the impression formed. Therefore, the scores of overall stereotype and two dimensions of female college students were still a bit higher, but there was no significant difference in genders. Moreover, future studies can appropriately expand the sample size to more effectively illustrate the phenomenon.

\section{CONCLUSION}

(1) The stereotypes of college students on the only child are "wasteful, confident, short-tempered, lonely, haughty, and strong dependent".

(2) College students from rural areas have deeper stereotypes on only child than urban college students.

(3) The only-child college students and non-only-child students show a clear "outside group derogatory effect" in only-child stereotype.

(4) There is no gender difference in college students' stereotype on only child.

\section{ACKNOWLEDGMENT}

*This study is funded by MOE (Ministry of Education in China) Project of Humanities and Social Sciences (Project No.17YJAZH092).

Corresponding author: Liang Jieshuang, 13283484577@163.com

\section{REFERENCES}

[1] Lian SF. Implicit Social Cognitive: A Study of the Theory and Experiment of Stereotype [D]. East China Normal University, 2013.

[2] Plaza M, Boiché J, Brunel L, et al. Sport = Male... But Not All Sports: Investigating the Gender Stereotypes of Sport Activities at the Explicit and Implicit Levels [J]. Sex Roles, 2018, 76(3):1-16.

[3] Bae H, Sang HJ, Han S, et al. Influence of negative age stereotypes and anti-aging needs on older consumers' consumption-coping behaviours: A qualitative study in South Korea [J]. International Journal of Consumer Studies, 2018.

[4] Alt NP, Chaney KE, Shih MJ. "But that was meant to be a compliment!" Evaluative costs of confronting positive racial stereotypes [J]. Group Processes \& Intergroup Relations, 2018:136843021875649.

[5] Feather NT, Simon JG. Stereotypes about male and female success and failure at sex-linked occupations [J]. Journal of Personality, 2010, 44(1):16-37.

[6] Lawrence Nyman. The Identification of Birth Order Personality Attributes [J]. Journal of Psychology Interdisciplinary \& Applied, 1995, 129(1):51-59.

[7] Herrera NC, Zajonc RB, Wieczorkowska G, et al. Beliefs about birth rank and their reflection in reality.[J]. Journal of Personality \& Social Psychology, 2003, 85(1):142.

[8] Wang P, Ge GH, Yan JW, et al. An Empirical Study on College Students' Stereotype of Only Child [J]. Social Psychological Science, 2011(z1):229-234.

[9] Bao LP. Stereotypes of Only Child in China: Structure, Source, and Consequences [D]. East China Normal University, 2010.

[10] Xiao FQ, Feng XT. 30 Years of Research on the Only Child in China: Two Perspectives and Their Limitations [J]. Nanjing Social Sciences, 2010(7):45-52.

[11] Cui Y. A Study of College Students' Stereotype on the Only Child [D]. Guangzhou University, 2013. 